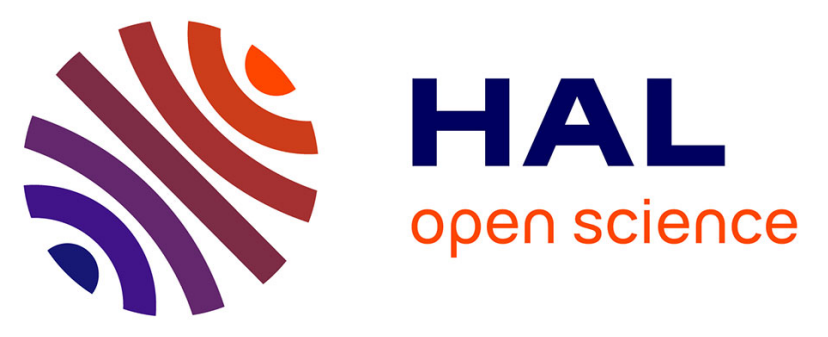

\title{
Correlations between computational fluid dynamics and clinical evaluation of nasal airway obstruction due to septal deviation: An observational study
}

Thomas Radulesco, Lionel Meister, Gilles Bouchet, Arthur Varoquaux, Jérome Giordano, Julien Mancini, Patrick Dessi, Pierre Perrier, Justin Michel

\section{To cite this version:}

Thomas Radulesco, Lionel Meister, Gilles Bouchet, Arthur Varoquaux, Jérome Giordano, et al.. Correlations between computational fluid dynamics and clinical evaluation of nasal airway obstruction due to septal deviation: An observational study. Clinical Otolaryngology, 2019, 44, pp.603 - 611. 10.1111/coa.13344 . hal-03198714

\section{HAL Id: hal-03198714 https://hal.science/hal-03198714}

Submitted on 15 Apr 2021

HAL is a multi-disciplinary open access archive for the deposit and dissemination of scientific research documents, whether they are published or not. The documents may come from teaching and research institutions in France or abroad, or from public or private research centers.
L'archive ouverte pluridisciplinaire HAL, est destinée au dépôt et à la diffusion de documents scientifiques de niveau recherche, publiés ou non, émanant des établissements d'enseignement et de recherche français ou étrangers, des laboratoires publics ou privés. 


\title{
Correlations between computational fluid dynamics and clinical evaluation of nasal airway obstruction due to septal deviation: An observational study
}

\author{
Thomas Radulesco ${ }^{1,2}$ (D) | Lionel Meister ${ }^{2}$ | Gilles Bouchet ${ }^{2}$ | Arthur Varoquaux $^{3,4}$ | \\ Jérôme Giordano $^{2}$ | Julien Mancini ${ }^{5,6}$ | Patrick Dessi ${ }^{1}$ | Pierre Perrier ${ }^{2}$ | Justin Michel ${ }^{1,2}$
}

${ }^{1}$ Department of Oto-Rhino-Laryngology and Head and Neck Surgery, APHM, La Conception University Hospital, Marseille, France

${ }^{2}$ IUSTI, Aix-Marseille University, Marseille, France

${ }^{3}$ Department of Medical Imaging, APHM, La Conception University Hospital, AixMarseille University, Marseille, France

${ }^{4}$ Biophysics and Nuclear Medicine, European Center for Research in Medical Imaging, La Timone University Hospital, Aix-Marseille University, Marseille, France

${ }^{5}$ Biostatistics Department, APHM, La Timone University Hospital, Marseille, France

${ }^{6}$ Inserm, IRD, UMR912 SESSTIM, AixMarseille University, Marseille, France

\section{Correspondence}

Thomas Radulesco, Department of OtoRhino-Laryngology and Head and Neck Surgery, La Conception University Hospital, 147 Bd Baille, 13005 Marseille, France. Email: thomas.radulesco@ap-hm.fr

\begin{abstract}
Objectives: The primary objective of this study was to determine how computational fluid dynamics (CFD) could be correlated to clinical evaluation of nasal airway obstruction (NAO) in a population of patients with symptomatic septal deviation (SD). The secondary objective was to determine whether CFD could define which side was the more obstructed.
\end{abstract}

Design: This was an observational study.

Settings: Few publications have attempted to correlate CFD with clinical evaluation of NAO. This correlation would permit validation and improved interpretation. This study was performed in a university research laboratory specialised in fluid mechanics.

Participants: We included patients referred for septal surgery at our centre. Age range was 19-58 years. Preoperative CT scans were performed. All patients with non-structural causes of NAO such as rhinitis, sinusitis or tumoral/autoimmune processes (ie, not due to anatomic obstruction) were excluded.

Main outcome measurement: For each nasal fossa, we compared CFD data (total pressure, heat flux, wall shear stress, temperatures, velocity and nasal resistances) with both patient perception scores and rhinomanometry using the Spearman correlation test $\left(r_{s}\right)$. Perception scores were graded from 0/4 to $4 / 4$ on each side, based on the patient interview. We also compared CFD-derived nasal resistances with rhinomanometry-derived nasal resistances.

Results: Twenty-two patients complaining of NAO with SD were analysed, and 44 analyses were performed comparing each side with its CFD data. Regarding correlations with patient perception scores, the best values we found were heat flux measures $\left(r_{\mathrm{s}}=0.86\right)$. Both rhinomanometry and CFD-calculated nasal resistances had strong correlations with subjective perception scores $\left(r_{\mathrm{s}}=0.75, P<0.001\right.$ and $r_{\mathrm{s}}=0.6$, $P<0.001$, respectively). We found a statistically significant difference between RMM-NR and CFD-NR $(P=0.003)$. Heat flux analysis allowed us to distinguish the more obstructed side (MOS) and the less obstructed side (LOS) in $100 \%$ of patients. Conclusion: This study aimed to enhance our ability to interpret CFD-calculated data in the nasal airway. It highlights and confirms that heat flux measures are very closely 
correlated to patient perception in cases of SD. It also helps to distinguish the more obstructed side from the less obstructed side and could contribute to further CFD studies.

\section{1 | INTRODUCTION}

Nasal airway obstruction (NAO) is a common symptom leading many patients to seek a medical consultation and occasionally undergo surgical procedures. ${ }^{1}$ Septal deviation (SD) is one of the main causes of NAO. ${ }^{2}$

Clinical evaluation of NAO is usually carried out by patient interview, self-questionnaires and various physical tests designed to quantify NAO. ${ }^{3}$ Anterior active rhinomanometry is a physical test performed in many centres to calculate resistance to the airflow in the nasal cavity. ${ }^{4}$

Computational fluid dynamics (CFD) is a recent tool for modelling the nasal cavity as well as for analysing air conditioning and airflow. ${ }^{5}$ Over the past 10 years, more and more authors have assessed the nasal airway using CFD. ${ }^{6} \mathrm{New}$ measurements, such as heat flux (HF) and wall shear stress (WSS), are computable by CFD in addition to usual data such as nasal resistances. ${ }^{7}$

However, only a few publications have attempted to correlate CFD with clinical evaluation of NAO and these studies were usually based on a limited number of cases or on healthy subjects. ${ }^{6,8}$ In our view, the correlation between CFD and clinical evaluation of NAO (patient perception and rhinomanometry) would permit validation and improved interpretation. Regarding NAO, patients often complain of unilateral impairment. This is convenient for correlating CFD data as they can be easily calculated on each side: the more obstructed side (MOS) and the less obstructed side (LOS). However, the most frequently used self-questionnaires are quality-of-life evaluation tools, which is why they do not investigate lateralisation of the functional impairment, thus making it difficult to correlate them with CFD-calculated data. ${ }^{3}$

The primary objective of this study was to determine how CFD could be correlated to clinical evaluation of NAO in a population of patients with symptomatic SD. To do so, we researched the correlations between CFD and patient perception on one hand, and CFD and rhinomanometric data on the other for each of the nasal cavities.

The secondary objective of the study was to determine whether CFD could define which side was the MOS and the LOS.

\section{2 | METHODS}

\section{1 | Ethical standards}

All patients gave written consent before participating in the study, which was conducted according to the Declaration of Helsinki. Authorisation to conduct this study was obtained from the Ethical Committee of our institution (Assistance Publique des Hôpitaux de Marseille, N²017-14-12-005).

\section{Keypoints}

- Septal deviation is one of the main causes of nasal airway obstruction.

- Computational fluid dynamics is a recent tool for modelling the nasal cavity as well as for analysing air conditioning and airflow. Thanks to developments and technical progress in recent years, it is now possible to perform computational fluid dynamics on the nasal airway.

- The correlation between computational fluid dynamics and clinical evaluation of nasal airway obstruction would permit validation and improved interpretation.

- This study aims to enhance our ability to interpret CFDcalculated data in the nasal airway. It highlights and confirms that heat flux measures are very closely correlated to patient perception in cases of SD.

- We found that CFD-computed nasal resistances were strongly correlated with patient perception. However, CFD-calculated nasal resistances had low correlations with rhinomanometry in our series.

\subsection{Patient selection}

All patients were referred for septal surgery at our centre between January 2017 and September 2018. Age range was 19-58 years (mean 37 years). Preoperative CT scans were obtained using a low dose protocol on a multi-detector CT scanner (Aquilion Prime, Canon Medical Systems) using a cranio-caudal helical acquisition. Fixed parameters were used in accordance with the industrial engineer: $80 \times 0.5 \mathrm{~mm}$ detectors, FOV: extra-small $180 \mathrm{~mm}, 40 \mathrm{~mm}$ collimation, 0.5 seconds revolution time, pitch of $0.625 \mathrm{~mm} /$ rotation, $100 \mathrm{kV}$ tube voltage, DPL target of $50 \mathrm{mGy} \mathrm{cm}$, scout view auto-exposure of mAs intensity, FC30 bone filter, Adaptive Iterative Dose Reduction-3D standard reconstruction. Voxel dimensions were $0.35 \times 0.35 \times 0.5 \mathrm{~mm}\left(0.61 \mathrm{~mm}^{3}\right)$.

\section{3 | Exclusions}

All patients with non-structural causes of NAO such as rhinitis, sinusitis or tumoral/autoimmune processes (ie, not due to anatomic obstruction) were excluded. We excluded patients presenting symptoms alternating from one side to the other as this can create bias, especially regarding CFD-NR ${ }^{9}$ We also excluded patients with the same perception score on both sides, in order to clinically determine a MOS and a LOS for each patient. 


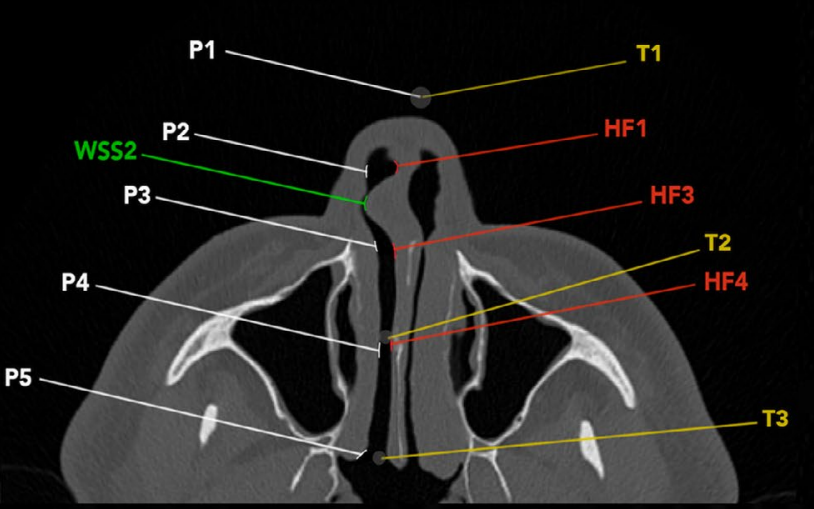

AXIAL VIEW

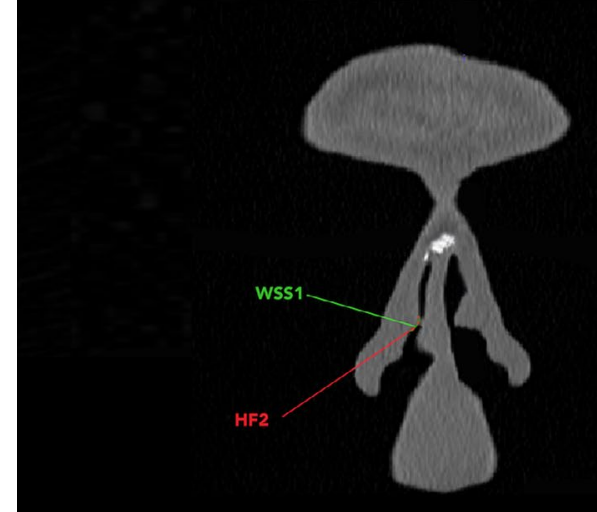

CORONAL VIEW

FIGURE 1 Example of CT scan in axial and coronal view showing where CFD data were calculated on the more obstructed side. $\mathrm{P} 1=\mathrm{OPa}$ and $\mathrm{T} 1=19^{\circ} \mathrm{C}$ for every patient. HF, Heat Flux; $\mathrm{T}$, Temperature; TP, Total Pressure; WSS, Wall Shear Stress

\subsection{Clinical evaluation of NAO}

\subsection{1 | Patient perception scores}

In all patients, subjective perception of nasal airflow was quantified separately on each nasal cavity: 0 = "no obstruction," 1 = "slight obstruction," 2 = "moderate obstruction," 3 = "severe obstruction" and 4 = "total obstruction." The more obstructed side was abbreviated to MOS. The less obstructed side was abbreviated to LOS. The definition of the LOS and MOS was based on the subjective scores. Clinical evaluation was performed 1 month before surgery, in the absence of any intercurrent infectious episode.

\subsection{2 | Rhinomanometry}

Anterior active rhinomanometry (without vasoconstriction) was performed before surgery. No procedures (eg, Cottle or Bachman tests) were performed in order to avoid deforming the nasal anatomy. The same rhinomanometer was used for all patients (Otopront ${ }^{\circledR}$ Rhinon-sys ${ }^{\circledR}$
Happersberger Otopront GmbH 2008). Right and left nasal resistances were calculated. Nasal resistances obtained using rhinomanometry were measured at a pressure drop of $150 \mathrm{~Pa}$ and are abbreviated to RMM-NR

\section{5 | Creation of 3-dimensional models}

3D reconstructions were obtained using ITK-SNAP (3.6.0). The procedure was as follows: (a) importation of CT scan images (DICOM formats), (b) segmentation process using the half-maximum height protocol (IMAGEJ software version 1.440) to determine the boundaries of anatomical structures and (c) nasal surface extraction. No smoothing algorithm was applied. The half-maximum height protocol offers an objective process to delimit a reproducible interface between two tissues. ${ }^{10}$ This method included pixels from -1024 to -400 Hounsfield Units. Paranasal sinuses were removed manually during the segmentation process.

\section{6 | CFD protocol}

CFD was performed using STAR-CCM ${ }^{\circledR}$ software (CD-ADAPCO-www. cd-adpaco.com). The computational domain was the Boolean union of extracted surface and a $3 \mathrm{~cm}$-diameter sphere centred on the tip of the nose. The aim of this sphere was to impose a pressure boundary condition far from the nostrils, thus allowing a non-imposed airflow close to the nasal entrance.

TABLE 1 Correlations of CFD data with patient perception

\begin{tabular}{|c|c|c|c|}
\hline & $r_{s}$ & $95 \% \mathrm{Cl}$ & $P$ \\
\hline \multicolumn{4}{|c|}{ Total pressure } \\
\hline P2 & 0.31 & $0.12 ; 0.64$ & 0.041 \\
\hline P3 & -0.47 & $-0.77 ;-0.38$ & $0.001^{*}$ \\
\hline P4 & -0.33 & $-0.6 ;-0.1$ & $0.002^{*}$ \\
\hline P5 & -0.02 & $-0.34 ; 0.38$ & 0.89 \\
\hline \multicolumn{4}{|l|}{ Heat flux } \\
\hline HF1 & $0.51^{\mathrm{a}}$ & $0.32 ; 0.77$ & $<0.001^{*}$ \\
\hline HF2 & $0.65^{\mathrm{a}}$ & $0.47 ; 0.81$ & $<0.001^{*}$ \\
\hline HF3 & $0.86^{b}$ & $0.57 ; 0.91$ & $<0.001^{*}$ \\
\hline HF4 & $0.71^{a}$ & $0.44 ; 0.83$ & $<0.001^{*}$ \\
\hline \multicolumn{4}{|c|}{ Temperature } \\
\hline T2 & $0.53^{\mathrm{a}}$ & $0.34 ; 0.76$ & $<0.001^{*}$ \\
\hline T3 & 0.44 & $0.13 ; 0.70$ & $0.003^{*}$ \\
\hline \multicolumn{4}{|l|}{ Velocity } \\
\hline Vmax & 0.26 & $0.04 ; 0.76$ & 0.11 \\
\hline \multicolumn{4}{|c|}{ Wall shear stress } \\
\hline WSS1 & 0.05 & $-0.28 ; 0.38$ & 0.75 \\
\hline WSS2 & $0.52^{\mathrm{a}}$ & $0.32 ; 0.77$ & $<0.001^{c}$ \\
\hline
\end{tabular}

Note: HF3 had the best match with patient perception. $r_{\mathrm{s}}=$ Spearman correlation test.

a Strong correlations.

bery strong correlations.

*Significant results $(P<0.004$ after Bonferroni correction). 

Total Pressure $(\mathrm{Pa})$
(A) Total Pressure

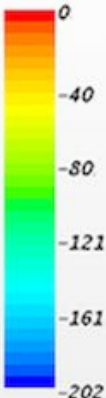

$x y$

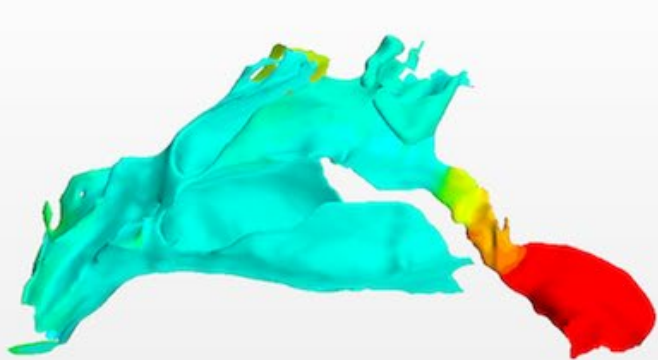

Right

Most Obstructed Side

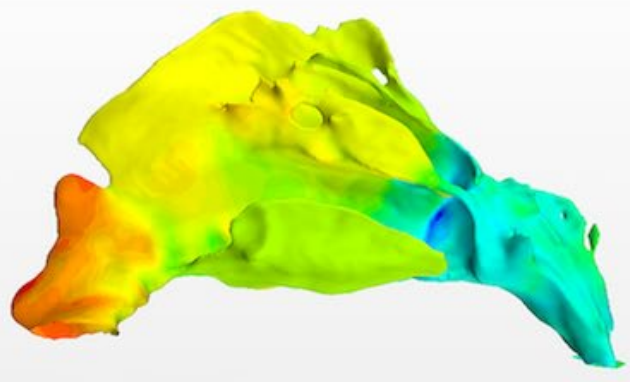

Left

Less Obstructed Side
Boundary Heat Flux $(W / m \wedge 2)$

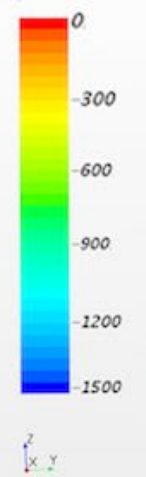

(B) Heat Flux
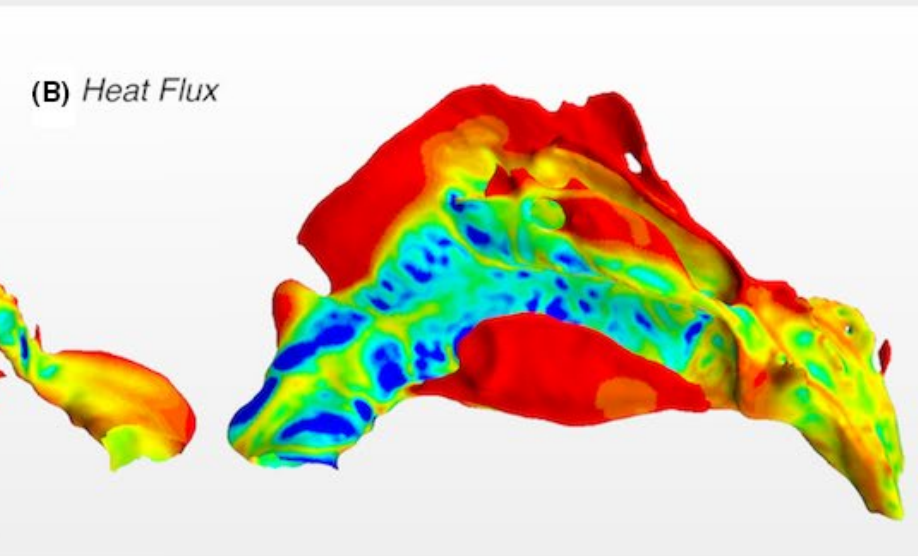

Wall Shear Stress: Magnitude $(\mathrm{Pa})$
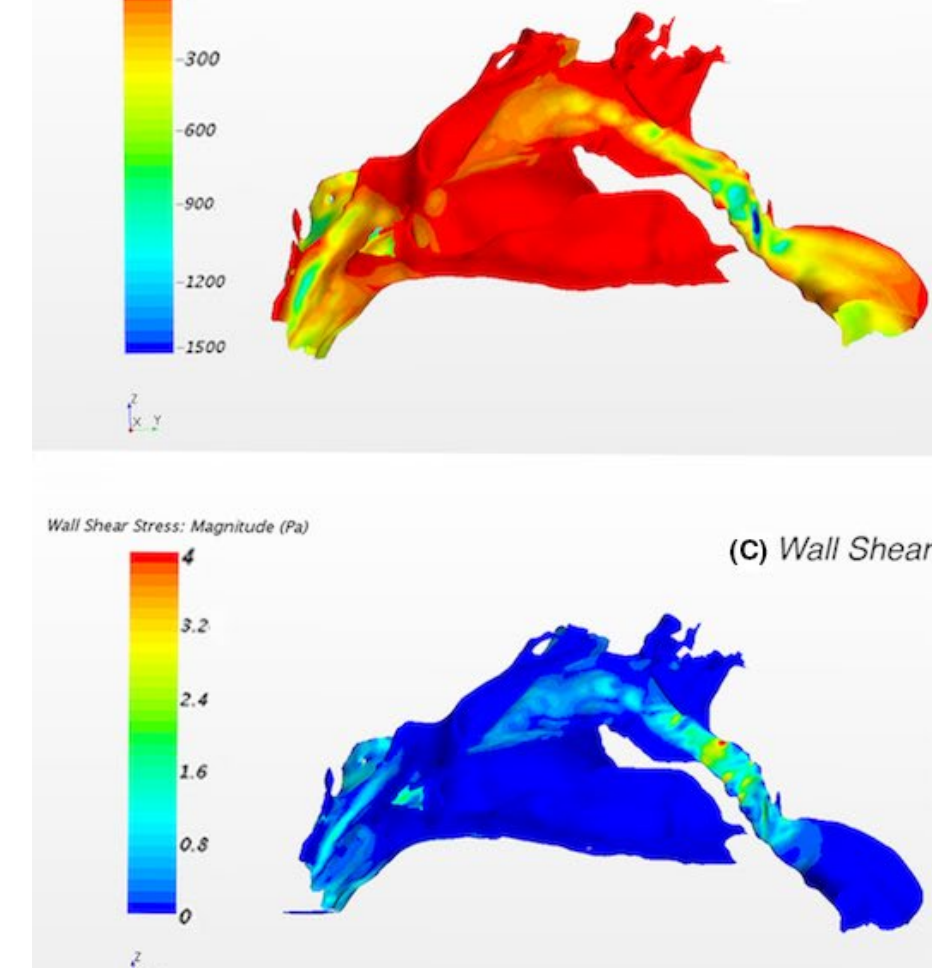

Stress

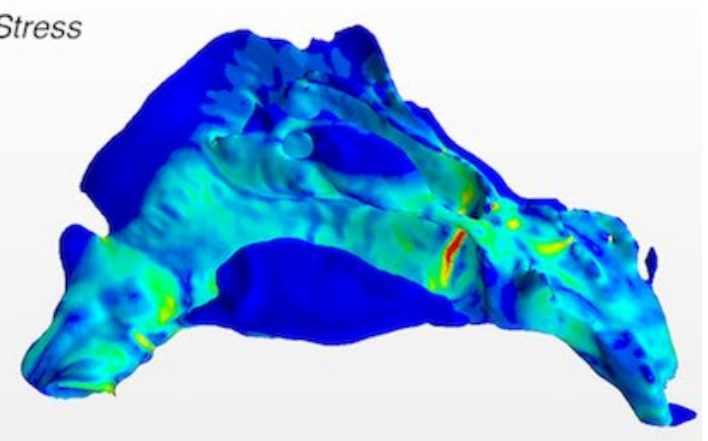

Total Pressure (Pa)

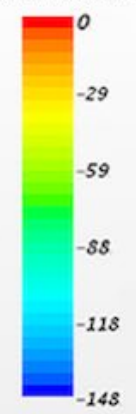

tixy

(D) Streamlines

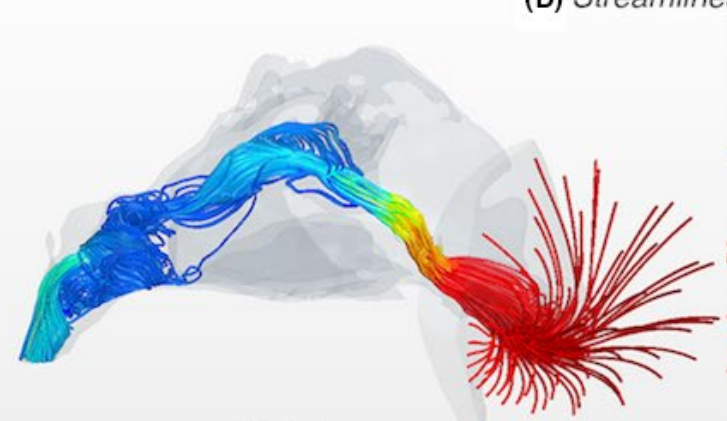

Right

Most Obstructed Side

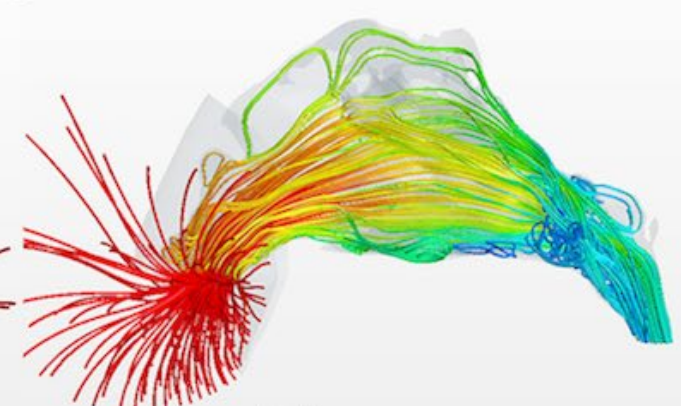

Left

Less Obstructed Side 
FIG URE 2 Lateral views of MOS (Right side) and LOS (Left side) according to (A) total pressure (Pa), (B) heat flux (W/m2), (C) wall shear stress $(\mathrm{Pa})$ and $(\mathrm{D})$ streamlines. Streamlines are coloured according to total pressure. The patient complained of right side "Total Obstruction" (4/4). On the left side, he reported "No obstruction" (0/4). On the MOS, we observed a strong Pressure drop and decreased Heat Flux. WSS1 and 2 were null and lower, respectively, on the MOS

Volume mesh was performed using a polyhedral mesher with parameters defined after a convergence mesh study: the prism layer (total thickness $=0.16 \mathrm{~mm}$ ) included 10 prismatic cells with 1.1 prism layer stretching ratio.

We defined the following computational hypothesis: airflow to standard conditions for temperature $\left(19^{\circ} \mathrm{C}\right)$ and atmospheric pressure (101325 Pa). Air was considered to be an incompressible Newtonian fluid with density $\rho=1.225 \mathrm{~kg} / \mathrm{m}^{3}$ and viscosity $\mu=1.8 \times 10^{-5}$ Pa seconds.

We considered the flow to be laminar. Steady computation was used, with a segregated solver and second-order accuracy in space. Sinonasal surface was a non-slip wall. Wall temperature was $34^{\circ} \mathrm{C} .{ }^{11}$ An imposed atmospheric pressure (reference value) was defined on the sphere surface (101 $325 \mathrm{~Pa}$ ). We analysed total pressure (TP) where TP = static pressure + dynamic pressure. Nasopharynx was a pressure outlet with an imposed pressure. In case of re-entry, the temperature of air in the nasopharynx was $37^{\circ} \mathrm{C}$. The differential pressure imposed in the nasopharynx was $-150 \mathrm{~Pa}$. CFD-calculated nasal resistances were called CFD-NR CFD-NR were calculated for the right and left side. Nasal resistances were expressed as $R=\Delta P / V$, where $\Delta P$ is the pressure differential between the nostril and the rhinopharynx and $\mathrm{V}$ is the airflow rate, expressed in $\mathrm{Pa} \mathrm{s} / \mathrm{mL}$. The pressure drop used to compute nasal resistance was total pressure differential.

A total of 30 CFD variables were collected for each patient, 15 on each side (Figure 1):

All measurements in axial view were performed $1.5 \mathrm{~cm}$ from the nasal floor on the septal wall. Total pressure, heat flux and WSS were measurement averages within a circular wall region of $1 \mathrm{~cm}^{2} . \mathrm{P} 1, \mathrm{P} 2$, P3, P4 and P5 were the pressure differentials with respect to atmospheric pressure. Pressures were measured in the ambient air (atmospheric pressure $=101325 \mathrm{~Pa}, \mathrm{P} 1=0 \mathrm{~Pa}$ ), $0.1 \mathrm{~cm}$ before the junction between upper lateral and lower lateral cartilages (nasal valve area; P2), $1 \mathrm{~cm}$ after maximum SD on MOS (or symmetrically for LOS; P3), $2 \mathrm{~cm}$ before the choana (the posterior third of the nasal septum; P4) and at the choana (P5). Heat flux (ie, the rate of heat transfer across a surface per unit of time and area) was measured at the entrance to the nose $(1 \mathrm{~cm}$ before the junction between upper lateral and lower lateral cartilages, on the nostril side; HF1), $0.1 \mathrm{~cm}$ before the junction between upper lateral and lower lateral cartilages (nasal valve area; HF2), $1 \mathrm{~cm}$ after maximum SD on MOS (or symmetrically for LOS; HF3) and $2 \mathrm{~cm}$ before the choana (posterior third of the nasal septum; HF4). Average HF measures were mean HF values calculated for both sides.

WSS was measured $0.1 \mathrm{~cm}$ before the junction between upper lateral and lower lateral cartilages (nasal valve area; WSS1) and at the maximum SD, depending on patient's deviation (WSS2).

Maximum velocity was assessed for each nasal fossa (Vmax). Temperatures were recorded in ambient air (T1), in the middle meatus (after the SD for MOS, symmetrically for LOS; T2) and at the choana (T3).

\section{7 | Statistical analyses}

Results were analysed using Microsoft Office Excel. Statistical calculations were performed using PAST software (Oyvind Hammer, University of Oslo, Norway). To compare CFD-NR and RMM-NR, statistical differences were assessed using a paired $t$ test. Comparisons between NAO and CFD variables were made using the Spearman correlation test $\left(r_{\mathrm{s}}\right)$. The correlation was considered perfect if $\left|r_{s}\right|=1$, very strong if $\left|r_{s}\right|>0.8$, strong if $0.5>\left|r_{s}\right|>0.8$, moderate if $0.2>\left|r_{\mathrm{s}}\right|>0.5$, low if $\left|r_{\mathrm{s}}\right|<0.2$ and null if $r_{\mathrm{s}}=0$. The 95\% confidence intervals of Spearman's rank correlation coefficients were computed by bootstrapping using the RVAideMemoire package for R3.5 (R Foundation for Statistical Computing). Comparisons between nasal cavity MOS and LOS were made using paired Wilcoxon test. $P$ values $<0.004$ were considered to be statistically significant after Bonferroni correction. Pearson correlation coefficient was used to compare RMM-NR and CFD-NR

\section{3 | RESULTS}

\section{1 | Population}

We selected 22 patients complaining of NAO with SD. Most of them had an anterior SD. We were thus able to perform 44 analyses comparing each side with its CFD data. Regarding patient perception scores, we found for MOS a severe obstruction score (mean score \pm standard deviation $=3.18 \pm 0.80$ ); For LOS, we found a low obstruction score (mean score \pm standard deviation $=0.95 \pm 0.79$ ) The difference between MOS and LOS was statistically significant $(P<0.001)$.

\section{2 | Correlation of CFD with subjective perception of nasal airflow}

\subsection{1 | Pressures, heat flux, temperatures, velocities, wall shear stress}

Regarding correlations with patient perception, we found a very strong correlation for heat flux values after SD (HF3; Figures S2 and S3; Table 1). We also found a strong correlation with all other HF values, T2 and WSS2. Moderate correlations were found for P2, P3, P4, T3 and Vmax. Correlations were low or non-significant for P5, WSS1 and Vmax. After Bonferroni correction, only P2 became non-significant $(P>0.004)$.

\subsection{2 $\quad$ RMM-NR and CFD-NR}

Both RMM-NR and CFD-NR had strong correlations with subjective scores $\left(r_{\mathrm{s}}=0.75, P<0.001\right.$ and $r_{\mathrm{s}}=0.6, P<0.001$, respectively). 


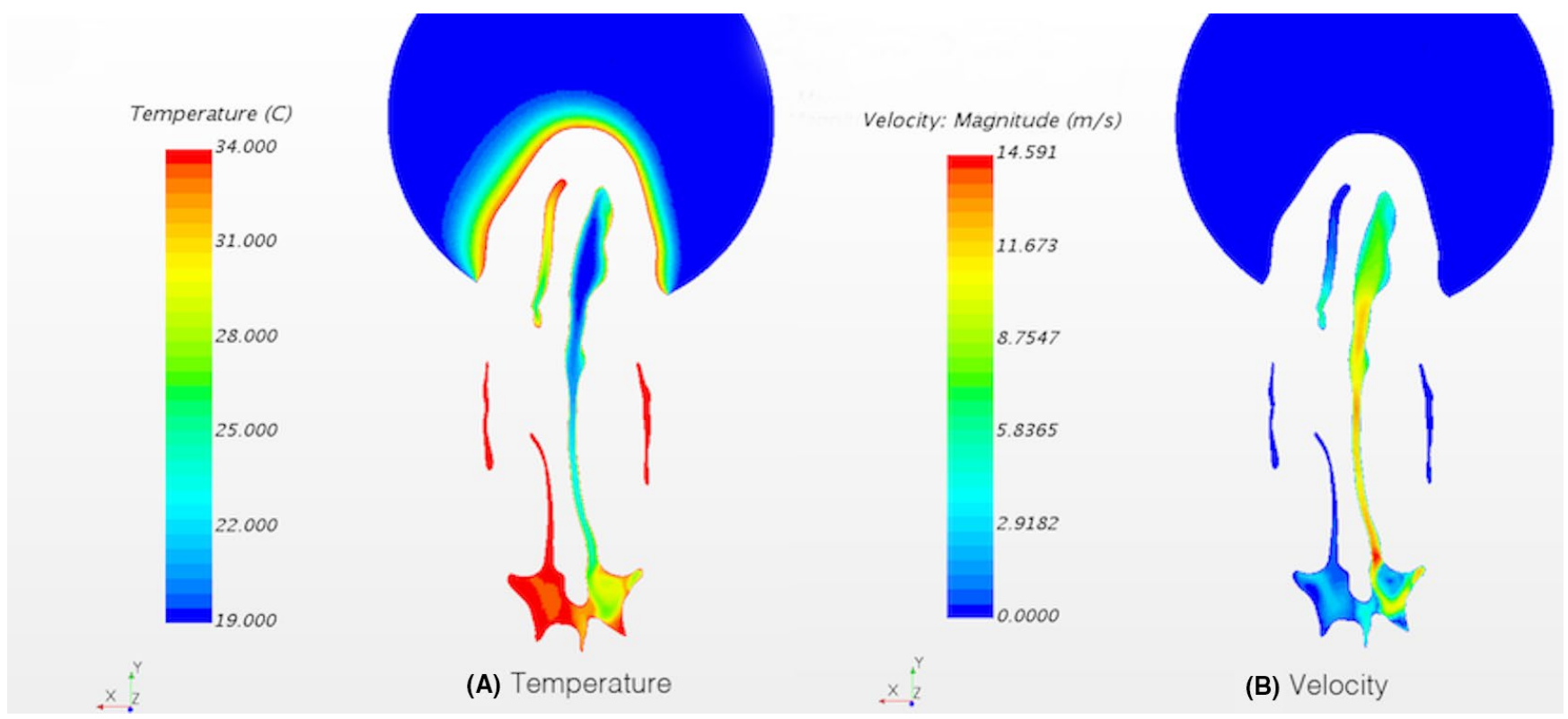

FIG URE 3 A, Temperatures $\left({ }^{\circ} \mathrm{C}\right)$ and $(B)$ velocities $(\mathrm{m} / \mathrm{s})$. in axial view for the same patient (Right-side obstruction). Temperatures were lower in the LOS. However, velocities were higher on the LOS when NAO was total

\subsection{Comparison between MOS and LOS}

\subsection{1 | Pressures, heat fluxes, temperatures, velocities, wall shear stress}

Regarding total pressure, we found a big pressure drop after SD (P3) in MOS (Figures 2, 3, and 4A; Table 23.1; Video S1). The difference was statistically significant comparing MOS and LOS for P3 $(P<0.001)$. However, we found no statistically significant differences for P2, P4 and P5. There was a strong modification of HF, moving closer to $0 \mathrm{~W} / \mathrm{m}^{2}$, after SD on MOS (HF3, Figure 4B).

The difference was statistically significant comparing MOS and LOS for HF1, HF2, HF3 and HF4 ( $P<0.001)$. Average heat flux measures in LOS were higher than MOS thus allowing us to identify LOS and MOS in $100 \%$ of patients. At T2 (Figure $4 \mathrm{C}$ ), mean temperatures were $28.5 \pm 3.6^{\circ} \mathrm{C}$ and $23.3 \pm 2.8^{\circ} \mathrm{C}$, respectively, for MOS and LOS. At T3, mean temperatures were $30.9 \pm 1.9^{\circ} \mathrm{C}$ and $29 \pm 2.3^{\circ} \mathrm{C}$, respectively, for MOS and LOS. Differences were statistically significant at T2 between MOS and LOS $(P<0.001)$. We also found a strong correlation between HF and temperatures $\left(r_{\mathrm{s}}=0.56, P<0.001\right)$. Maximum velocities were higher on MOS. The difference between MOS and LOS was not statistically significant $(P=0.039)$. Comparing WSS, they were statistically higher on MOS in WSS2 values but not in WSS1 $(P=0.065 ;$ Figure 4D).

\subsection{2 | RMM-NR and CFD-NR}

RMM-NR were mean $1.8 \pm 2.2 \mathrm{~Pa} \mathrm{~s} / \mathrm{mL}$ for MOS. RMM-NR were mean $0.6 \pm 0.37 \mathrm{~Pa} \mathrm{~s} / \mathrm{mL}$ for LOS $(P=0.01)$. CFD-NR were mean $0.8 \pm 1.17 \mathrm{~Pa} \mathrm{~s} / \mathrm{mL}$ for MOS. CFD-NR were mean $0.23 \pm 0.1 \mathrm{~Pa} \mathrm{~s} / \mathrm{mL}$ for LOS $(P=0.03)$.
We found a statistically significant difference between RMM-NR and CFD-NR ( $P=0.003$, Figure S1). The Pearson correlation coefficient was $r=0.145(P=0.3)$ between RMM-NR and CFD-NR RMMNR in LOS were lower than MOS in 91\% of analyses. CFD-NR in LOS were lower than MOS in $82 \%$ of analyses. CFD-calculated flow rates in LOS were higher than MOS in $82 \%$ of analyses.

\section{4 | DISCUSSION}

\subsection{Synopsis of new findings}

The ability to analyse airflow and air conditioning within the nasal cavities offers new perspectives in rhinology. Over the past 10 years, many CFD studies have investigated the nose, first in healthy or cadaveric subjects, and then in patients. ${ }^{12-14}$ The analysis and interpretation of CFD-calculated data must be correlated with the patient's clinical experience. ${ }^{6}$ To that end, CFD must be compared with already existing tests or examinations, especially relative to new data such as HF or WSS.

\subsection{Clinical applicability of the study}

Clinical evaluation of NAO remains difficult. Many tools have been developed in recent years, and patient reported outcome has become more and more important in functional procedures. Evaluation can be performed subjectively, often by self-questionnaires. The NOSE, SNOT-22 and ENS6Q self-questionnaires are the most used in the literature. ${ }^{9,14,15}$ Despite being widely validated in the literature, these questionnaires do not lateralise MOS and LOS although, in most cases, patients with NAO complain more about one side than about the other. Furthermore, CFD analysis is predominantly performed unilaterally. ${ }^{16}$ It is not logical, therefore, to compare a 


\section{Total Pressure}
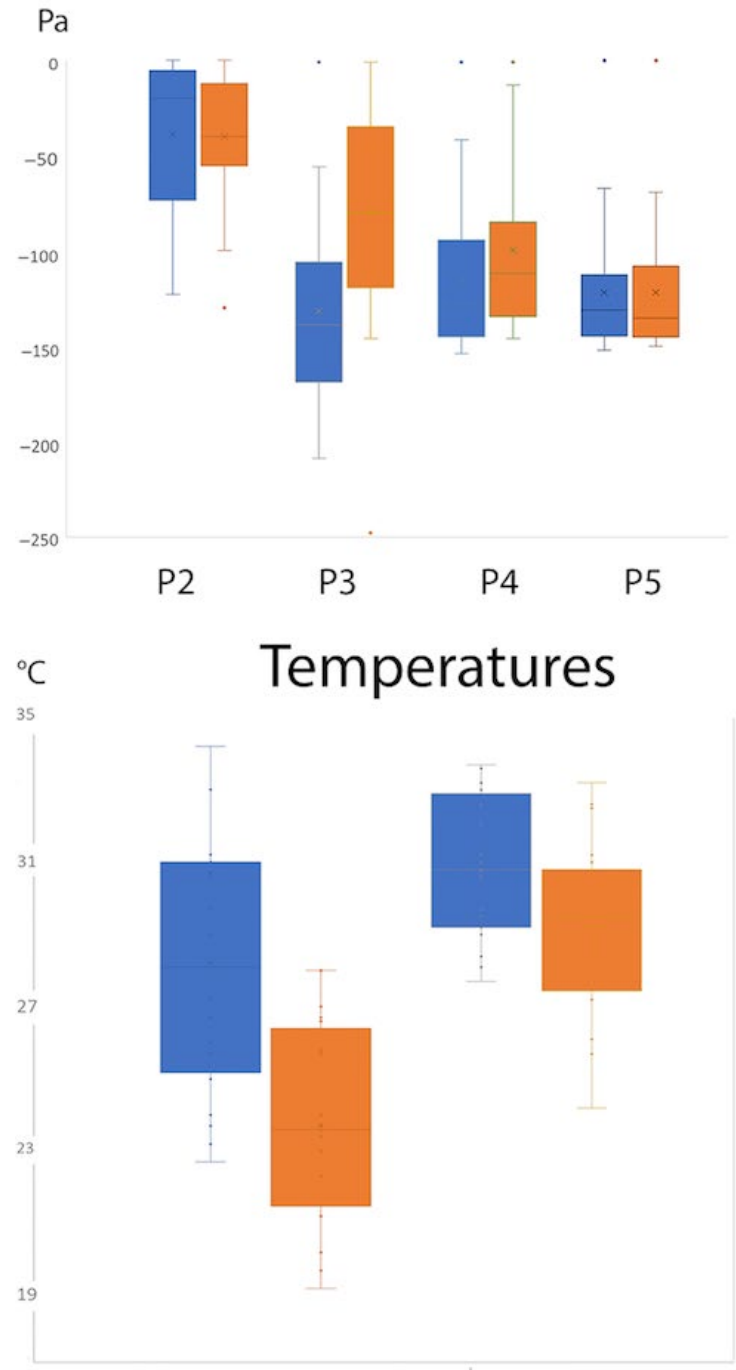

T2
HF1

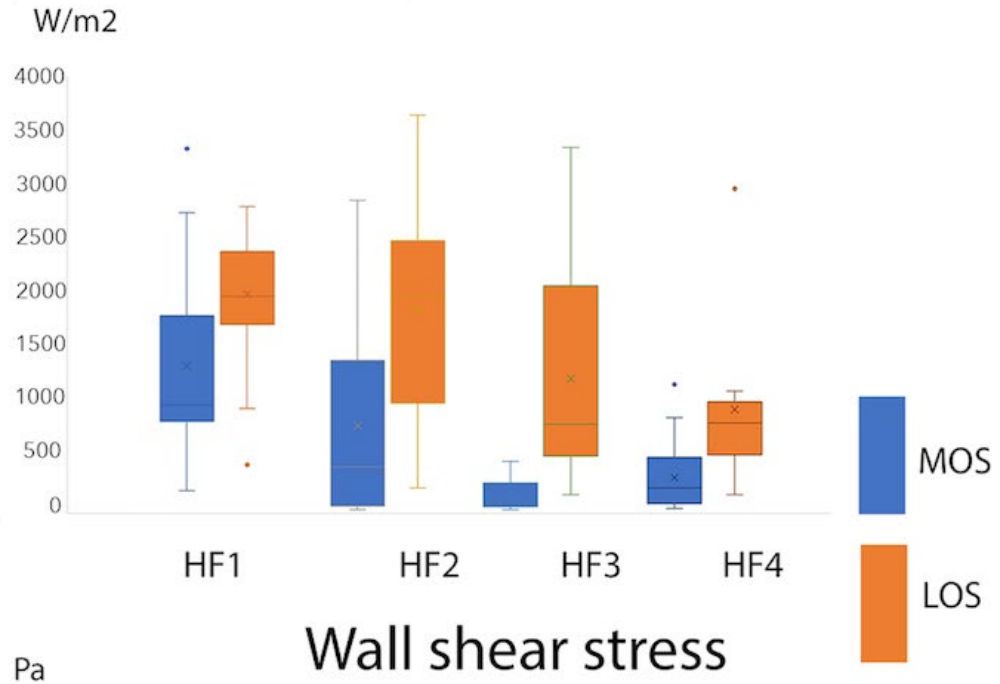

\section{Heat Flux}

Pa

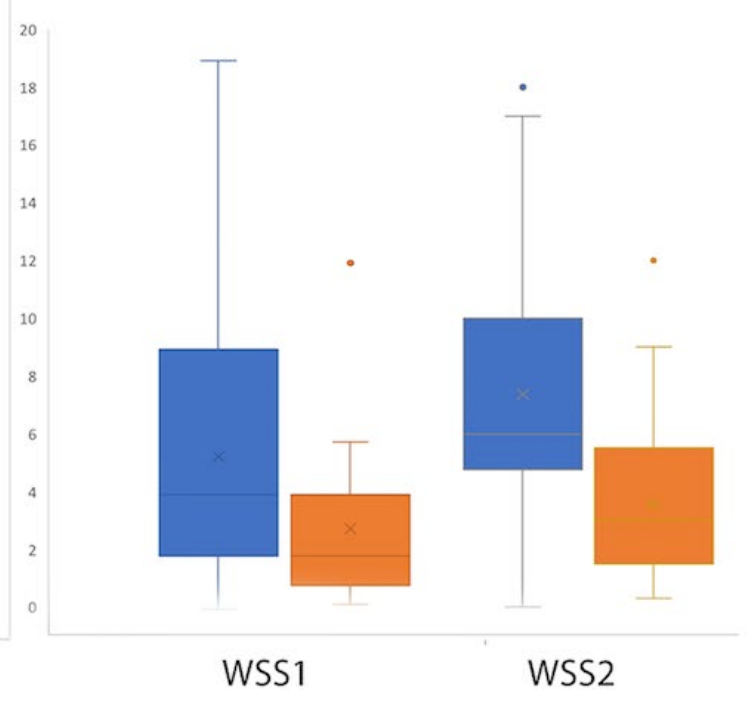

FIGURE 4 Mean values in the cohort of 22 patients: total pressure, heat flux, temperatures and wall shear stress are compared using boxplots according to MOS and LOS. A huge total pressure and heat flux drop (P3, HF3) were found after the septal deviation in MOS

unilateral CFD analysis with a global clinical feeling. For this reason, we found it useful to make separate clinical evaluations of MOS and LOS so as to compare with their CFD data. Establishing the correlation between CFD data and patients' clinical perceptions appears fundamental in order to better interpret CFD. Our study used a convenience sample of patients presenting a septal deviation, without any other cause of nasal involvement. This must be kept in mind when interpreting our results.

\subsection{Comparison with other studies}

Kimbell et $\mathrm{al}^{16,17}$ and Kim et $\mathrm{al}^{18}$ also found big changes in airflow characteristics on MOS after SD (Video S1). Similarly for HF, which decreased after SD and was closely correlated with patient perception (Figures 2 and 4). The decrease of HF after SD can be explained by reduced airflow in this area responsible for less heat exchange between cool air $\left(19^{\circ} \mathrm{C}\right)$ and mucosa $\left(34^{\circ} \mathrm{C}\right)$.
Although there are different ways of measuring HF (Total HF, Peak HF, SAHF50), many authors have found a strong correspondence between HF and patient perception, ${ }^{17,19,20}$ whatever the method adopted. We also noted this strong correlation. This finding reinforces the idea that the mucosal cooling effect plays a large part in NAO perception, and that the latter is probably multifactorial and not dependent exclusively on nasal resistances as suggested for many years. ${ }^{11}$ In our study, average heat flux measures were always higher in LOS, thus suggesting that heat flux measures can distinguish MOS from LOS. Since HF is dependent on air and wall temperatures, it is scientifically logical to find a strong correlation between $\mathrm{HF}$ and temperatures $\left(r_{\mathrm{s}}=0.56\right)$. It is also logical that temperature differences between MOS and LOS are lower at T3 than at T2 as air temperature has nearly achieved the wall temperature in both sides by the time inspired air reaches the choana.

Regarding WSS, there was a good correlation with subjective scores for the WSS2 measured on the maximum SD but not in the 
TAB LE 2 Comparisons between mean CFD values for more obstructed side and less obstructed side

\begin{tabular}{|c|c|c|c|}
\hline & MOS & LOS & $P$ \\
\hline \multicolumn{4}{|c|}{ Subjective scores } \\
\hline & $3.18 \pm 0.80$ & $0.95 \pm 0.79$ & $<0.001^{*}$ \\
\hline \multicolumn{4}{|c|}{ Total pressure $(\mathrm{Pa})$} \\
\hline P2 & $-34.6 \pm 40.0$ & $-42.9 \pm 31.8$ & 0.52 \\
\hline P3 & $-128.5 \pm 47.6$ & $-75.4 \pm 42.0$ & $0.003^{*}$ \\
\hline P4 & $-114.9 \pm 33.7$ & $-99.3 \pm 38.5$ & 0.11 \\
\hline P5 & $-123.6 \pm 24.9$ & $-123.8 \pm 24.6$ & 0.775 \\
\hline \multicolumn{4}{|c|}{ Heat flux $\left(W / m^{2}\right)$} \\
\hline HF1 & $1069 \pm 872$ & $2192 \pm 867$ & $<0.001^{*}$ \\
\hline HF2 & $731 \pm 941$ & $1952 \pm 864$ & $0.001^{*}$ \\
\hline HF3 & $153 \pm 212$ & $1290 \pm 947$ & $<0.001^{*}$ \\
\hline HF4 & $276 \pm 308$ & $944 \pm 709$ & $<0.001^{*}$ \\
\hline \multicolumn{4}{|c|}{ Temperature $\left({ }^{\circ} \mathrm{C}\right)$} \\
\hline $\mathrm{T} 2$ & $28.5 \pm 3.6$ & $23.3 \pm 2.8$ & $<0.001^{*}$ \\
\hline T3 & $30.9 \pm 1.9$ & $29.0 \pm 2.3$ & 0.007 \\
\hline \multicolumn{4}{|c|}{ Velocity (m/s) } \\
\hline Vmax & $13.0 \pm 4.0$ & $10.2 \pm 4.0$ & 0.039 \\
\hline \multicolumn{4}{|c|}{ Wall shear stress (Pa) } \\
\hline WSS1 & $5.68 \pm 6.15$ & $2.54 \pm 1.99$ & 0.065 \\
\hline WSS2 & $7.21 \pm 4.78$ & $2.89 \pm 2.23$ & $0.002^{*}$ \\
\hline
\end{tabular}

Note: P2, P4 and P5 and WSS1 showed no statistical difference between MOS and LOS.

Abbreviations: LOS, Less Obstructed Side; MOS, More Obstructed Side. *Significant results $(P<0.004$ after Bonferroni correction).

nasal valve area (WSS1). Kimbell et $\mathrm{al}^{17}$ reported a correlation with patient perception measuring WSS on the entire MOS.

Regarding velocities, discordant results were found in our series which sometimes displayed higher velocities in LOS. ${ }^{13}$ Moreover, Vmax was poorly correlated with patient perception. Velocity and WSS are very dependent on anatomic variations. These discrepancies for WSS1 and Vmax can be explained by an "ON-OFF" effect in the event of total NAO. Logically, the greater the deviation, the higher the WSS1 and Vmax. However, in the event of absence of airflow due to totally obstructive septal deviation, WSS1 and Vmax are necessarily null and therefore lower in MOS than in LOS (Figure 3).

Nasal resistance is one of the most used data for assessing NAO perception prior to surgery (septoplasty, inferior turbinate hypertrophy or functional rhinoplasty). However, few studies have sought to compare RMM-NR and CFD-NR. Those studies that have been performed analyse only small cohorts or healthy subjects. ${ }^{8,21,22}$ This is the first study to compare CFD-NR and RMM-NR in a large cohort of patients with NAO. While establishing a good correlation between patient perception and both RMM-NR and CFD-NR, the correlation between CFD-NR and RMM-NR was poor $(r=0.14)$ in our series and lower than in Zhao's studies $(r=0.41$ and $r=0.53) .{ }^{20,21}$ However, Zhao analysed only healthy volunteers. In our study, we used total pressure differential to compute nasal resistance. This can explain in part why CFD-NR was statistically different from RMM-NR More studies need to be performed on this topic, on larger series, including NAO causes such as inferior turbinate hypertrophies or nasal valve collapses.

Indeed, using a small convenient sample clearly limits the statistical power of our study. Great care is needed when calculating CFD-NR: using a steady flow and a non-deformable model may have an impact on CFD-NR Moreover, the presence of a strong nasal cycle could bias CFD-NR analysis. Although the inferior turbinates can be reduced by applying vasoconstrictors, this procedure distorts reality. To overcome this problem, Gaberino et al $^{9}$ proposed virtual modelling to correct the nasal cycle: the correlation between CFD-NR and patient perception was greatly increased.

\section{4 | Limits}

To date, CFD can only analyse static disorders related to nasal ventilation. However, it is well known that ventilatory disorders can be dynamic, especially regarding the nasal valve. ${ }^{23}$ These disorders appear only above an airflow threshold involving dynamic nasal valve collapse. To date, CFD in the nasal airway does not assume deformable walls.

We used a steady flow simulating continuous inspiration. This model is quite different from clinical reality. ${ }^{4}$ CFD can calculate these inspiration/expiration cycles, even if the computing times are much longer. Importantly, we analysed inspiratory and not expiratory resistance. This choice was made because, in most cases, patients complain only of impairment due to inspiration. We acknowledge using a small series (in terms of statistical power) and a non-validated perception score. Moreover, patients and assessors were not blinded to the findings. We used a convenience sample subject to selection bias, which is not representative of the global population.

\section{5 | CONCLUSION}

This study aimed to enhance our ability to interpret CFD-calculated data in the nasal airway. Despite the small number of patients, this study highlights and confirms that heat flux measures are closely correlated to patient perception in cases of SD. It also helps to distinguish the more obstructed side from the less obstructed side. This should encourage further CFD studies, on larger series, including other NAO causes such as inferior turbinate hypertrophies or nasal valve collapses.

\section{ACKNOWLEDGEMENTS}

To Amidex and Mr Morgan for linguistic assistance.

\section{CONFLICT OF INTEREST}

None to declare. 


\section{ORCID}

Thomas Radulesco (iD https://orcid.org/0000-0002-5939-5372

\section{REFERENCES}

1. Villwock JA, Kuppersmith RB. Diagnostic algorithm for evaluating nasal airway obstruction. Otolaryngol Clin North Am. 2018;51(5):867-872.

2. Teixeira J, Certal V, Chang ET, Camacho M. Nasal septal deviations: a systematic review of classification systems. Plast Surg Int. 2016;2016:7089123.

3. Rhee JS, Sullivan CD, Frank DO, Kimbell JS, Garcia G. A systematic review of patient-reported nasal obstruction scores: defining normative and symptomatic ranges in surgical patients. JAMA Facial Plast Surg. 2014;16(3):219.

4. Vogt K, Wernecke K-D, Behrbohm H, Gubisch W, Argale M. Four-phase rhinomanometry: a multicentric retrospective analysis of 36,563 clinical measurements. Eur Arch Oto-Rhino-Laryngol. 2016;273(5):1185-1198.

5. Kim SK, Na Y, Kim J-I, Chung S-K. Patient specific CFD models of nasal airflow: overview of methods and challenges. J Biomech. 2013;46(2):299-306.

6. Leite $S$, Jain R, Douglas RG. The clinical implications of computerised fluid dynamic modelling in rhinology. Rhinology 2019;57(1):2-9.

7. Leong SC, Chen XB, Lee HP, Wang DY. A review of the implications of computational fluid dynamic studies on nasal airflow and physiology. Rhinology. 2010;48(2):139-145.

8. Lu J, Han D, Zhang L. Accuracy evaluation of a numerical simulation model of nasal airflow. Acta Otolaryngol. 2014;134(5):513-519.

9. Gaberino C, Rhee JS, Garcia GJ. Estimates of nasal airflow at the nasal cycle mid-point improve the correlation between objective and subjective measures of nasal patency. Respir Physiol Neurobiol. 2017;238:23-32.

10. Spoor CF, Zonneveld FW, Macho GA. Linear measurements of cortical bone and dental enamel by computed tomography: applications and problems. Am J Phys Anthropol. 1993;91(4):469-484.

11. Lindemann J, Tsakiropoulou E, Scheithauer MO, Konstantinidis I, Wiesmiller KM. Impact of menthol inhalation on nasal mucosal temperature and nasal patency. Am J Rhinol. 2008;22(4):402-405.

12. Li C, Farag AA, Maza G, et al. Investigation of the abnormal nasal aerodynamics and trigeminal functions among empty nose syndrome patients. Int Forum Allergy Rhinol. 2018;8(3):444-452.

13. Liu T, Han D, Wang J, et al. Effects of septal deviation on the airflow characteristics: using computational fluid dynamics models. Acta Otolaryngol. 2012;132(3):290-298.

14. Shadfar S, Shockley WW, Fleischman GM, et al. Characterization of postoperative changes in nasal airflow using a cadaveric computational fluid dynamics model: supporting the internal nasal valve. JAMA Facial Plast Surg. 2014;16(5):319-327.
15. Li C, Farag AA, Leach J, et al. Computational fluid dynamics and trigeminal sensory examinations of empty nose syndrome patients. Laryngoscope. 2017;127(6):E176-E184.

16. Kimbell JS, Garcia GJ, Frank DO, Cannon DE, Pawar SS, Rhee JS. Computed nasal resistance compared with patient-reported symptoms in surgically treated nasal airway passages: a preliminary report. Am J Rhinol Allergy. 2012;26(3):e94-98.

17. Kimbell JS, Frank DO, Laud P, Garcia GJ, Rhee JS. Changes in nasal airflow and heat transfer correlate with symptom improvement after surgery for nasal obstruction. J Biomech. 2013;46(15):2634-2643.

18. Kim SK, Heo GE, Seo A, Na Y, Chung SK. Correlation between nasal airflow characteristics and clinical relevance of nasal septal deviation to nasal airway obstruction. Respir Physiol Neurobiol. 2014;192:95-101.

19. Sullivan CD, Garcia GJ, Frank-Ito DO, Kimbell JS, Rhee JS. Perception of better nasal patency correlates with increased mucosal cooling after surgery for nasal obstruction. Otolaryngol Head Neck Surg. 2014;150(1):139-147.

20. Zhao K, Jiang J, Blacker K, et al. Regional peak mucosal cooling predicts the perception of nasal patency. Laryngoscope. 2014;124(3):589.

21. Zhao K, Jiang J, Blacker K, et al. In response: regional peak mucosal cooling predicts the perception of nasal patency: Mucosal Cooling and Nasal Patency. The Laryngoscope. 2014;124(3):589-595.

22. Zachow S, Muigg $P$, Hildebrandt $T$, Doleisch H, Hege H-C. Visual exploration of nasal airflow. IEEE Trans Vis Comput Graph. 2009;15(6):1407-1414.

23. Maalouf $R$, Bequignon $E$, Devars du Mayne $M$, et al. A functional tool to differentiate nasal valve collapse from other causes of nasal obstruction: the FRIED test. J Appl Physiol Bethesda Md 1985. 2016;121(1):343-347.

\section{SUPPORTING INFORMATION}

Additional supporting information may be found online in the Supporting Information section at the end of the article.

How to cite this article: Radulesco T, Meister L, Bouchet G, et al. Correlations between computational fluid dynamics and clinical evaluation of nasal airway obstruction due to septal deviation: An observational study. Clin Otolaryngol. 2019;00:1-9. https://doi.org/10.1111/coa.13344 